\title{
Funções polinomiais na estimativa da eficiência técnica e agronômica de uso do nitrogênio sobre a produtividade de grãos de aveia
}

\author{
Juliana Aozane da Rosa ${ }^{1}$ \\ Rúbia Diana Mantai ${ }^{2}$ \\ Adriana Roselia Kraisig ${ }^{3}$ \\ José Antonio Gonzalez da Silva ${ }^{4}$ \\ Ivan Ricardo Carvalho ${ }^{5}$ \\ Márcia Sostmeyer Jung ${ }^{6}$ \\ Vanessa Pansera ${ }^{7}$ \\ Odenis Alessi ${ }^{8}$ \\ Departamento de Ciências Exatas e Engenharias e Departamento de Estudos Agrários, UNIJUÍ, Ijuí, RS
}

Resumo. O uso de modelos matemáticos nos processos de biossistemas possibilitam o avanço de novas tecnologias à agricultura. Para alcançar a máxima expressão de produtividade dos grãos de aveia é necessário o ajuste de técnicas de manejo que proporcionem melhor eficiência de uso de nitrogênio pela planta. O objetivo do estudo é definir por regressão linear a eficiência agronômica de aproveitamento do nitrogênio pela relação dose fornecida e produto obtido e estimar por regressão quadrática a máxima eficiência técnica de expressão da produtividade de grãos pelo uso do nutriente. O estudo foi realizado em delineamento de blocos casualizados com quatro repetições seguindo um modelo fatorial $4 \times 2$, para doses de nitrogênio $\left(0,30,60\right.$ e $\left.120 \mathrm{~kg} \mathrm{ha}^{-1}\right)$ e cultivares de aveia (Barbarasul e Brisasul), em sistemas de sucessão soja/aveia e milho/aveia. A eficiência agronômica mostra independente da condição de ano agrícola um coeficiente ângular médio de $7,8 \mathrm{~kg} \mathrm{ha}^{-1}$ de produtividade de grãos a cada quilograma de nitrogênio fornecido e um coeficiente linear inicial ao redor de $2715 \mathrm{~kg} \mathrm{ha}^{-1}$ de grãos, no sistema soja/aveia. Já, no sistema milho/aveia, o coeficiente angular médio é de $13,5 \mathrm{~kg} \mathrm{ha}^{-1}$ de produtividade de grãos a cada quilograma de nitrogênio fornecido com coeficiente linear inicial médio de $1900 \mathrm{~kg} \mathrm{ha}{ }^{-1}$ de grãos. Assim, taxa de eficiência agronômica da aveia pelo uso de nitrogênio promove maior incremento na produtividade de grãos no sistema soja/aveia, pois o coeficiente linear deste sistema é decisivo na obtenção de maior produtividade de grãos. Pela eficiência técnica, independente da condição de ano agrícola, o maior retorno da produtividade de grãos é obtido com a dose média 88 e $109 \mathrm{~kg} \mathrm{ha}^{-1}$ de nitrogênio em sistema soja/aveia e milho/aveia, respectivamente.

Palavras-chave. Avena sativa, Modelagem Matemática, Regressão, Sistemas de Cultivo, Sustentabilidade

\footnotetext{
1 juaozane@gmail.com

${ }^{2}$ rdmantai@yahoo.com.br

${ }^{3}$ maryshelei@yahoo.com.br

4 jagsfaem@yahoo.com.br

${ }^{5}$ carvalho.irc@gmail.com

${ }^{6}$ sostmeyerjungm@gmail.com

7 vpansera@hotmail.com

8 odenisalessi@hotmail.com
} 


\section{Introdução}

A modelagem matemática é uma ferramenta utilizada para transformar situações reais em representações matemáticas, cujas soluções facilitam o direcionamento de decisões à busca de eficiência e otimização. Assim, existe a necessidade de otimizar a produção de alimentos a partir de tecnologias que garantam produtividade com redução de custos e sustentabilidade aos agroecossistemas $[4,7]$.

Para a máxima expressão do potencial de produtividade dos grãos de aveia, é necessário o ajuste de técnicas de manejo que propiciem uma melhor eficiência de absorção e metabolização do nitrogênio pela planta, nutriente decisivo para o desenvolvimento, produtividade e qualidade $[2,8]$. $\mathrm{O}$ uso inadequado da adubação nitrogenada tem sido um dos fatores que mais têm restringido o incremento da produtividade de grãos no Brasil. Pequenas doses de nitrogênio limitam a produtividade e a qualidade, entretanto, altas doses podem ocasionar o acamamento da cultura, dificultando a colheita e reduzindo a produtividade $[11,13]$. Na busca por estratégias que propiciem a redução do emprego de fertilizantes industriais vinculada à elevada produtividade e qualidade de grãos de aveia, está o uso de modelos de regressões polinomiais. Estes modelos descrevem a relação existente entre variáveis a partir de uma série de dados observados, promovendo simulações e auxiliando na tomada de decisões quanto ao manejo e melhoria dos bioprocessos [6,9].

A utilização de modelos de regressões polinomiais podem possibilitar o conhecimento e a otimização da dinâmica de influência do nitrogênio sobre a aveia, determinando a taxa de variação de variáveis de interesse em função do nitrogênio, e a dose do nutriente que confere a máxima resposta, gerando suporte à validação de manejos que promovam maior sustentabilidade da agricultura. $\mathrm{O}$ objetivo do estudo é definir por regressão linear a eficiência agronômica de aproveitamento do nitrogênio pela relação dose fornecida e produto obtido e estimar por regressão quadrática a máxima eficiência técnica de expressão da produtividade de grãos pelo fornecimento de nitrogênio.

\section{Material e Métodos}

O experimento foi conduzido a campo, em Augusto Pestana, RS, Brasil. O delineamento experimental foi o de blocos casualizados com quatro repetições, seguindo um esquema fatorial 4 x 2, para doses de nitrogênio $\left(0,30,60\right.$ e $\left.120 \mathrm{~kg} \mathrm{ha}^{-1}\right)$ e cultivares de aveia (Barbarasul e Brisasul), totalizando 64 unidades experimentais nos sistemas de sucessão soja/aveia e milho/aveia. A produtividade de grãos foi obtida pelo corte de três linhas centrais de cada parcela no estádio de maturidade de colheita, com umidade de grãos ao redor de $22 \%$. As plantas foram trilhadas com colheitadeira estacionária e direcionadas ao laboratório para correção da umidade de grãos para $13 \%$; e pesagem para estimativa da produtividade de grãos ( $\left.\mathrm{PG}, \mathrm{kg} \mathrm{ha}^{-1}\right)$.

Ao atender aos pressupostos de homogeneidade e normalidade via testes de Bartlett, foi realizada análise de variância para detecção dos efeitos principais e de interação. Através do modelo de Scott e Knott foi realizado o teste de comparação de médias da produtividade de grãos, das combinações doses de nitrogênio com cultivares de aveia. Assim, para a eficiência agronômica foi necessário a utilização da regressão linear (1), sendo que a variável independente representa o produto avaliado, neste caso, a quantidade de nitrogênio e a variável dependente a produtividade de grãos.

$$
\hat{y}=\hat{b}_{0}+\hat{b}_{1} x+\epsilon
$$

Onde $\hat{y}$ é a variável dependente, $\mathrm{x}$ a variável independente, $\epsilon$ é o erro aleatório, $\hat{b}_{0}$ e $\hat{b}_{1}$ são parâmetros a serem estimados com a utilização do método dos mínimos quadrados.

A eficiência agronômica é obtida pelo coeficiente angular da equação linear, indicando a taxa de produtividade por unidade de nitrogênio fornecido. O coeficiente linear da equação também deve ser considerado, pois determina o ponto de partida do desempenho do nutriente [1]. Assim, a 
partir da regressão linear, foi possível encontrar a eficiência agronômica pela derivada da equação em relação a x, ou seja, a eficiência agronômica é determinada pela taxa de variação ou o coeficiente angular da equação, conforme a equação (2):

$$
\hat{y}^{\prime}=\hat{b}_{1}
$$

Os dados da produtividade de grãos foram também submetidos a análise de regressão quadrática, na elaboração de equações que permitiram estimar a máxima eficiência técnica da aveia pelo uso de nitrogênio para cada ano agrícola avaliado. Para a máxima eficiência técnica da produtividade de grãos, foi utilizada a equação quadrática (3), sendo x a quantidade de nitrogênio aplicado, e y a produtividade de grãos da aveia.

$$
\hat{y}=\hat{b}_{0}+\hat{b}_{1} x+\hat{b}_{2} x^{2}+\epsilon
$$

Onde $\mathrm{y}=$ variável dependente, $\mathrm{x}$ a variável independente, $\epsilon$ o erro aleatório, $b_{0}, b_{1}$ e $b_{2}$ são parâmetros a serem estimados com a utilização do métodos dos mínimos quadrados. Desta forma, a máxima eficiência técnica é obtida pela derivada da função quadrática homogênea (4) [14]. Deste modo, $\mathrm{x}$ representa a dose de nitrogênio que implica na maior produtividade $\mathrm{y}$, ou seja, a máxima eficiência técnica.

$$
x=\frac{-\hat{b}_{1}}{2 \hat{b}_{2}}
$$

Os procedimentos para os testes de médias e análise de rgressão linear e quadrática, foram realizadas separadamente para o sistema soja/aveia, com o auxílio do software GENES.

\section{Resultados e Discussão}

Na Tabela 1 na análise da produtividade de grãos no sistema soja/aveia, a eficiência agronômica através de uma regressão linear busca a relação do quilograma de nitrogênio fornecido por quilograma de produto obtido. Verifica-se que independente da condição de ano agrícola, uma amplitude variando de 7,0 a 9,8 e média 7,8 . Assim, a cada quilograma de nitrogênio fornecido, retorna 7,8 $\mathrm{kg}$ de produtividade de grãos. De modo geral, embora a produtividade de grãos mostre uma reduzida variação da eficiência pelo uso de nitrogênio, o coeficiente linear foi mais expressivo frente ao ponto de partida do aproveitamento do nitrogênio. Nesta perspectiva, destaca-se os anos 2011 e 2013. Já, para a produtividade de grãos no sistema milho/aveia, a eficiência agronômica mostrou, independente da condição de ano agrícola, uma amplitude variando de 9,4 a 16,3 com uma média de 13,5. Com os anos favoráveis de 2011 e 2013 indicando concomitantemente valores mais expressivos de coeficiente angular e linear. Além disso, resultados similares ao redor de $16 \mathrm{~kg}$ de produtividade de grãos por quilograma de nitrogênio fornecido, com valores de intercepto ao redor de $2300 \mathrm{~kg}$ de grãos. Esta condição evidencia redução da taxa de produtividade da condição favorável a desfavorável. De modo geral, independente de ano agrícola, há um incremento de 13,5 $\mathrm{kg} \mathrm{ha}^{-1}$ de produtividade de grãos a cada quilograma de nitrogênio, com uma expectativa média inicial de $1900 \mathrm{~kg} \mathrm{ha}^{-1}$ de grãos.

Nas Figuras 1 e 2, através da regressão quadrática é apresentada as estimativas da máxima eficiência técnica de uso do nitrogênio da principal variável de interesse, ou seja, a produtividade de grãos e destaca-se que em todas as equações foi observado que os pontos analisados estavam dentro do intervalo de confiança das distintas observações. Nesta perspectiva, na Figura 1, foi utilizado as equações de regressões no sistema soja/aveia, mostrando que o ano favorável de 2011 indicou a máxima eficiência técnica similar ao ano desfavorável de 2012 , com 82 e $86 \mathrm{~kg} \mathrm{ha}^{-1}$ de nitrogênio, respectivamente. No entanto, a simulação de 2011 evidencia uma produtividade de 
Tabela 1: Equação da eficiência agronômica e valores médios da produtividade de grãos de aveia em distintos anos de cultivo nos sitemas soja/aveia e milho/aveia.

\begin{tabular}{|c|c|c|c|c|c|c|c|c|}
\hline \multirow[t]{2}{*}{$\mathrm{y}$} & \multirow[t]{2}{*}{ Ano } & \multicolumn{4}{|c|}{ Valores médios/dose de $\mathrm{N}\left(\mathrm{kg} \mathrm{ha}^{-1}\right)$} & \multirow[t]{2}{*}{$\bar{y}$} & \multirow{2}{*}{$\begin{array}{c}\text { Equação } \\
\hat{y}=\hat{b}_{0}+\hat{b}_{1} x\end{array}$} & \multirow[t]{2}{*}{$\overline{R^{2}}$} \\
\hline & & 0 & 30 & 60 & 120 & & & \\
\hline \multicolumn{9}{|c|}{ Sistema soja/aveia } \\
\hline \multirow{7}{*}{ PG } & $2011(\mathrm{AF})$ & 2989 & 3694 & 4124 & 3938 & $3686 \mathrm{a}$ & $3308+7,2^{*} \mathrm{x}$ & 55 \\
\hline & $2012(\mathrm{AD})$ & 1745 & 2361 & 2751 & 2654 & $2378 \mathrm{c}$ & $2011+7,0^{*} \mathrm{x}$ & 62 \\
\hline & $2013(\mathrm{AF})$ & 3036 & 3721 & 4174 & 3994 & 3731 a & $3345+7,3^{*} \mathrm{x}$ & 57 \\
\hline & 2014 (AD) & 1645 & 2132 & 2426 & 2522 & $2181 \mathrm{c}$ & $1820+7,0^{*} \mathrm{x}$ & 80 \\
\hline & $2015(\mathrm{AI})$ & 2746 & 3361 & 3825 & 3871 & $3451 \mathrm{~b}$ & $2983+8,9^{*} \mathrm{x}$ & 76 \\
\hline & $2016(\mathrm{AI})$ & 2461 & 3279 & 3884 & 3717 & $3335 \mathrm{~b}$ & $2821+9,8^{*} \mathrm{x}$ & 62 \\
\hline & $\bar{x}$ & $2437 \mathrm{C}$ & $3091 \mathrm{~B}$ & $3531 \mathrm{~A}$ & 3449 A & 3127 & $2715+7,8^{*} \mathrm{x}$ & 65 \\
\hline \multicolumn{9}{|c|}{ Sistema milho/aveia } \\
\hline \multirow{7}{*}{ PG } & $2011(\mathrm{AF})$ & 1956 & 2956 & 3590 & 3984 & $3122 \mathrm{a}$ & $2277+16,1^{*} \mathrm{x}$ & 87 \\
\hline & $2012(\mathrm{AD})$ & 1313 & 1893 & 2229 & 2499 & $1984 \mathrm{c}$ & $1491+9,40^{*} \mathrm{x}$ & 88 \\
\hline & $2013(\mathrm{AF})$ & 2100 & 3144 & 3650 & 4183 & 3269 a & $2411+16,3^{*} \mathrm{x}$ & 89 \\
\hline & $2014(\mathrm{AD})$ & 1020 & 1631 & 2097 & 2313 & $1765 \mathrm{~d}$ & $1221+10,3^{*} \mathrm{x}$ & 86 \\
\hline & $2015(\mathrm{AI})$ & 1729 & 2552 & 3167 & 3479 & $2732 \mathrm{~b}$ & $1996+14,0^{*} \mathrm{x}$ & 86 \\
\hline & $2016(\mathrm{AI})$ & 1647 & 2598 & 3371 & 3512 & $2782 \mathrm{~b}$ & $1999+14,9{ }^{*} \mathrm{x}$ & 80 \\
\hline & $\bar{x}$ & $1628 \mathrm{C}$ & $2462 \mathrm{~B}$ & 3017 A & $3328 \mathrm{~A}$ & 2609 & $1900+13,5^{*} \mathrm{x}$ & 86 \\
\hline
\end{tabular}

$\mathrm{AF}=$ Ano favorável; $\mathrm{AD}=$ Ano desfavorável; $\mathrm{AI}=$ Ano intermediário; $R^{2}=$ Coeficiente de determinação (\%); ${ }^{*}=$ significativo a $5 \%$ de probabilidade de erro pelo teste $\mathrm{t}$; ns= Não significativo a $5 \%$ de probabilidade de erro pelo teste $\mathrm{t}$; Médias seguidas pelas mesmas letras minúsculas na coluna e maiúsculas na linha, constituem grupo estatisticamente homogêneo pelo modelo de Skott-Knott a $5 \%$ de probabilidade de erro.

grãos de $4200 \mathrm{~kg} \mathrm{ha}{ }^{-1}$, em relação a 2012 com simulação de $2841 \mathrm{~kg} \mathrm{ha}^{-1}$. Embora o uso de nitrogênio seja similar, a eficiência do produto foi muito expressiva, indicando a importância das relações ambientais a maior eficiência do uso de nitrogênio para a planta de aveia à elaboração da produtividade. Este fato se torna ainda mais evidente no ano favorável de cultivo de $2013 \mathrm{com}$ máxima eficiência técnica de uso do nitrogênio de $82 \mathrm{~kg} \mathrm{ha}^{-1}$ em relação ao ano desfavorável de 2014, com a máxima eficiência técnica de uso do nitrogênio com $104 \mathrm{~kg} \mathrm{ha}^{-1}$. Além da necessidade de maior uso de nitrogênio no ano de 2014 para a máxima produtividade, o resultado obtido foi muito inferior em comparação a 2013, utilizando uma dose mais reduzida do nutriente. Destacase que os anos intermediários de cultivo (2015 e 2016) mostraram similaridade da dose ótima de uso de nitrogênio e resultados também similares para máxima expressão da produtividade. Os resultados apresentados sugerem que o uso de doses ótimas à expressão da produtividade levem em consideração as condições ambientais.

Na Figura 2, está apresentada a estimativa da máxima eficiência técnica de uso do nitrogênio da principal variável de interesse, ou seja, a produtividade de grãos, em sistema milho/aveia, usando equações de regressão quadráticas. A máxima eficiência técnica de uso de nitrogênio é obtida pelo ponto máximo da curva quadrática da produtividade em função das doses de nitrogênio $[1,3,12]$. Nesta perspectiva, independente da condição de ano agrícola as máximas eficiências técnicas se mostraram similares, com valores entre 97 a $117 \mathrm{~kg} \mathrm{ha}^{-1}$ de nitrogênio, contudo, a eficiência do produto pelas condições de ano agrícola foi muito expressiva, indicando a importância das relações ambientais no uso de nitrogênio para a planta de aveia à elaboração da produtividade. Deste modo, em anos favoráveis, a máxima eficiência técnica de $111 \mathrm{~kg} \mathrm{ha}^{-1}$ de nitrogênio retorna uma produtividade de grãos superior a $4000 \mathrm{~kg} \mathrm{ha}{ }^{-1}$.

Em anos intermediários, a máxima eficiência técnica ao redor de $103 \mathrm{~kg} \mathrm{ha}^{-1}$ de nitrogênio 
Figura 1: Comportamento da produtividade de grãos de aveia e sua máxima eficiência técnica de uso do nitrogênio no sistema soja/aveia.

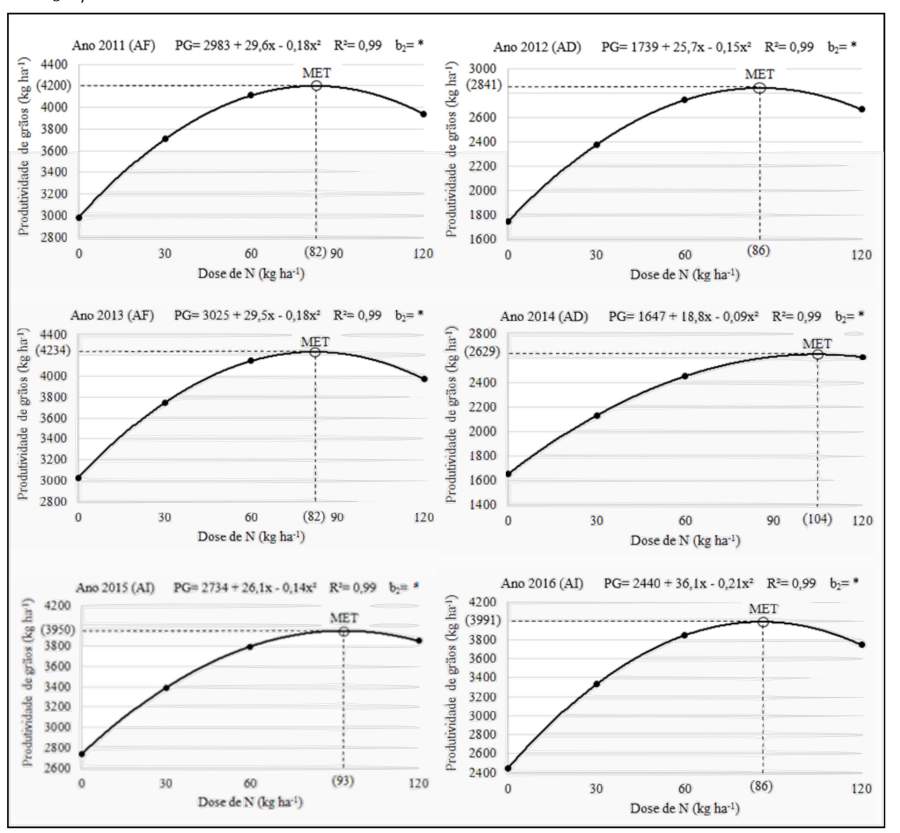

Figura 2: Comportamento da produtividade de grãos de aveia e sua máxima eficiência técnica de uso do nitrogênio no sistema milho/aveia.

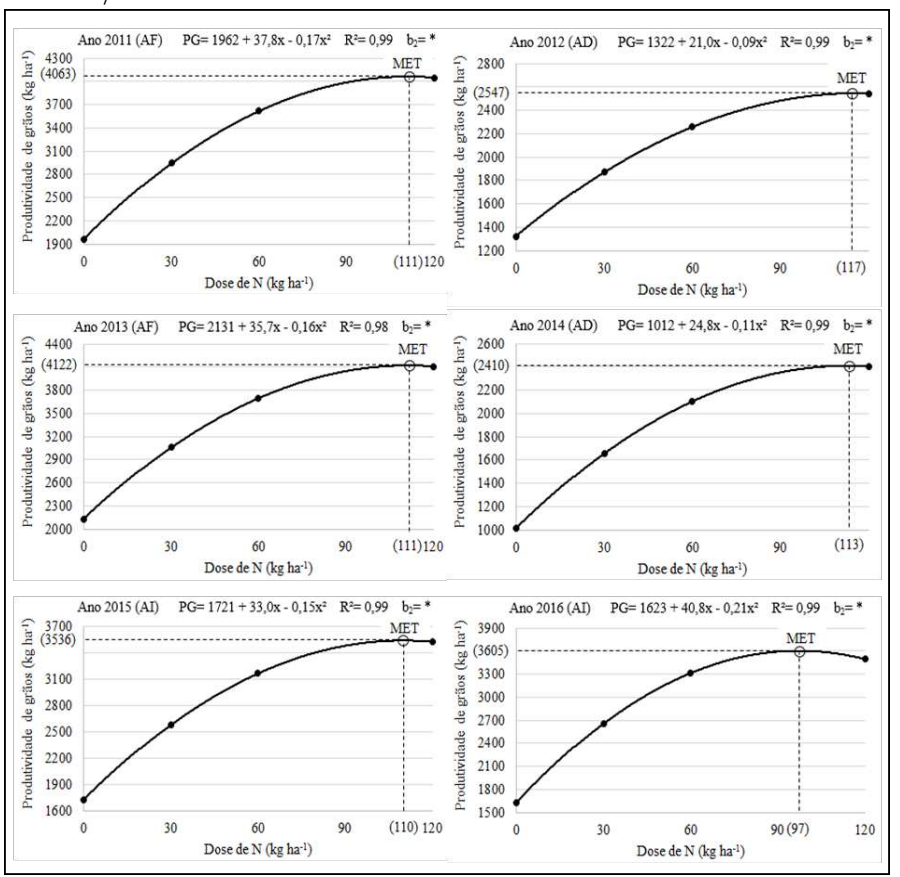


retorna uma produtividade de grãos ao redor de $3570 \mathrm{~kg} \mathrm{ha}^{-1}$. Em anos desfavoráveis, à máxima eficiência técnica ao redor de $115 \mathrm{~kg} \mathrm{ha}^{-1}$ de nitrogênio retorna uma produtividade de grãos ao redor de $2478 \mathrm{~kg} \mathrm{ha}^{-1}$. Portanto, uma amplitude de 97 a $117 \mathrm{~kg} \mathrm{ha}{ }^{-1}$ de nitrogênio, evidenciou uma amplitude de produtividade de 2410 a $4122 \mathrm{~kg} \mathrm{ha}^{-1}$ de grãos. Semelhante ao ocorrido no sistema soja/aveia, os resultados apresentados sugerem que o uso de doses ótimas à expressão da produtividade levem em consideração as condições ambientais no momento de aplicação do nutriente, e embasadas em previsões meteorológicas durante o ciclo de cultivo, na busca de maior retorno econômico e redução dos impactos ambientais.

O sistema de sucessão soja/aveia alcança eficiências agronômicas e técnicas com doses mais reduzidas do nutriente, em comparação ao sistema milho/aveia. Fato devido a rápida liberação de N-residual do sistema de sucessão soja/aveia, que beneficia a produtividade de grãos, mudando de maneira significativa a eficiência agronômica do uso do nitrogênio [1,10]. Em pesquisa que avalia a eficiência agronômica do fertilizante nitrogenado para produtividade de grãos em cultivares de aveia, destacou-se a cultivar URS Taura de maior eficiência com 4,68 kg de grãos produzidos por quilograma de nitrogênio fornecido, entretanto, com baixo coeficiente linear $\left(1544 \mathrm{~kg} \mathrm{ha}^{-1}\right)$ levando à redução da produtividade quando comparado às cultivares com menores coeficientes angulares [1]. Os mesmos autores, observaram que a máxima eficiência técnica de uso de nitrogênio é dada pela resposta de altos rendimentos com uma menor quantidade de nitrogênio. Em aveia, a máxima eficiência técnica de uso do nitrogênio foi obtida com $75 \mathrm{~kg} \mathrm{ha}^{-1}$ de nitrogênio [5]. Entretanto, outros autores, estudando cultivares de aveia, observaram que a máxima eficiência técnica de uso de nitrogênio é fortemente dependente das condições ambientais [2]. Esses autores relatam uma eficiência técnica máxima de uso do nitrogênio, obtida com $86 \mathrm{~kg} \mathrm{ha}^{-1}$ do nutriente, gerando uma produtividade de grãos de $4181 \mathrm{~kg} \mathrm{ha}^{-1}$ em um ano favorável, e uma máxima eficiência técnica de uso do nitrogênio com $119 \mathrm{~kg} \mathrm{ha}^{-1}$ atingindo uma produtividade de $2930 \mathrm{~kg} \mathrm{ha}^{-1}$ de grãos em um ano desfavorável. Estes resultados são similares ao encontrado neste trabalho, corroborando que a ampla faixa de produtividade de grãos está associada à alta variabilidade das condições de cultivo, sendo o fator ano o de maior influência.

\section{Conclusões}

A eficiência agronômica mostra independente da condição de ano agrícola um coeficiente ângular médio de $7,8 \mathrm{~kg} \mathrm{ha}^{-1}$ de produtividade de grãos a cada quilograma de nitrogênio fornecido e um coeficiente linear inicial ao redor de $2715 \mathrm{~kg} \mathrm{ha}^{-1}$ de grãos, no sistema soja/aveia. Já, no sistema milho/aveia, o coeficiente angular médio é de $13,5 \mathrm{~kg} \mathrm{ha}^{-1}$ de produtividade de grãos a cada quilograma de nitrogênio fornecido com coeficiente linear inicial médio de $1900 \mathrm{~kg} \mathrm{ha}^{-1}$ de grãos. Assim, taxa de eficiência agronômica da aveia pelo uso de nitrogênio promove maior incremento na produtividade de grãos no sistema soja/aveia, pois o coeficiente linear deste sistema é decisivo na obtenção de maior produtividade de grãos. Pela eficiência técnica, independente da condição de ano agrícola, o maior retorno da produtividade de grãos é obtido com a dose média 88 e $109 \mathrm{~kg}$ $\mathrm{ha}^{-1}$ de nitrogênio em sistema soja/aveia e milho/aveia, respectivamente.

\section{Referências}

[1] Arenhardt, E. G., Da Silva, J. A. G., Arenhardt, L. G., Da Silva, D. R., Gzergorczick, M. E., Ceolin, G. P., Stulp, C., Figueiredo, R. G., De Oliveira, A. C. Eficiência técnica e agronômica de cultivares de aveia em função da disponibilidade de nitrogênio. Científica, volume 45, p. 257-270, 2017. DOI: 10.15361/1984-5529.2017v45n3p257-270. 
[2] Da Silva, J. A. G., Goi Neto, C. J., Fernandes, S. B. V., Mantai, R. D., Scremin, O. B., Pretto, R. Eficiência de nitrogênio em aveia no rendimento de grãos com estabilidade. $R e$ vista Brasileira de Engenharia Agrícola e Ambiental, volume 20, p. 1095-1100, 2016. DOI: 10.1590/1807-1929/agriambi.v20n12p1095-1100.

[3] Mamann, A. T. W., Silva, J. A G., Scremin, O. B., Mantai, R. D., Scremin, A. H., Dornelles, E. F. Nitrogen efficiency in wheat yield through the biopolymer hydrogel. Revista Brasileira de Engenharia Agrícola e Ambiental, volume 702, p. 697-702, 2017.

[4] Mamann, A. T. W., da Silva, J. A. G, Binelo, M. O., Scremin, O. B., Kraisig, A. R., Carvalho, I. R., Argenta, C. V. Inteligência Artificial Simulando Produtividade de Grãos Durante o Desenvolvimento do Trigo Considerando Indicadores Biológicos e Ambientais. Journal of Agricultural Studies, volume 7, p. 197-212, 2019. ISSN: 2166-0379.

[5] Kolchinski, E. M., Schuch, L. O. B. Eficiência no uso do nitrogênio por cultivares de aveia branca de acordo com a adubação nitrogenada. Revista Brasileira de Ciência do Solo, volume 27, p. 1033-1038, 2003. DOI: 10.1590/S0100-06832003000600007.

[6] Pinnow, C., Benin, G., Viola, R., Da Silva, C. L., Gutkoski, L. C., Cassol, L. C. Qualidade industrial do trigo em resposta a adubação verde e doses de nitrogênio. Bragantia, volume 72 , p. 20-28, 2013. ISSN: 1678-4499.

[7] Sala, V. M. R., Freitas, S. D. S., Donzeli, V. P., Freitas, J. G., Gallo, P. B., Silveira, A. P. D. D. Ocorrência e efeito de bactérias diazotróficas em genótipos de trigo. Revista Brasileira de Ciência do Solo, volume 29, p. 345-352, 2005. DOI:10.1590/S0100-06832005000300004.

[8] Scremin, O. B., Da Silva, J. A. G., De Mamann, A. T. W., Mantai, R. D., Brezolin, A. P., Marolli, A. Eficiência de nitrogênio no rendimento de aveia através do biopolímero hidrogel. Revista Brasileira de Engenharia Agrícola e Ambiental, volume 21, p. 379-385, 2017. DOI: 10.1590/1807-1929/agriambi.v21n6p379-385.

[9] Seffrin, R., Araújo, E. C. de., Bazzi, C. L. Regression models for prediction of corn yield in the state of Paraná (Brazil) from 2012 to 2014. Acta Scientiarum. Agronomy, volume 40, p.1-11, 2018. DOI: 10.4025/actasciagron.v40i1.36494.

[10] Silveira, S. F., Hawerroth, M. C., Oliveira, D. C. da S., Woyann, L. G., Almeida, H. C. F., Luz, V. K., Thurow, L., Silva, R. M., Gutkoski, L. C., Maia, L. C., Oliveira, A. C. Heterosis and genetic parameters for grain quality in oat segregating populations. Scientia Agricola, volume 73, p. 471-477, 2016. DOI: 10.1590/0103-9016-2015-0129.

[11] Teixeira Filho, M. C. M., Buzetti, S., Andreotti, M., Arf, O., Benett, C. G. S. Doses, fontes e épocas de aplicação de nitrogênio em trigo irrigado em plantio direto. Pesquisa agropecuária brasileira, volume 45, p. 797-804, 2010. DOI: 10.1590/S0100-204X2010000800004.

[12] Todeschini, M. H., Milioli, A. S., Trevizan, D. M., Bornhofen, E., Finatto, T., Storck, L., Benin, G. Eficiência de uso do nitrogênio em cultivares modernas de trigo. Bragantia, volume 75, p. 351-361, 2016. DOI: 10.1590/1678-4499.385.

[13] Vasconcelos, C. N. Pastagens: implantação e manejo. Salvador: EBDA, 2006.

[14] Wendling, A., Eltz, F. L. F., Cubilla, M. M., Amado, T. J. C., Mielniczuk, J., Lovato, T. Recomendação de adubação nitrogenada para trigo em sucessão ao silho e soja sob sistema plantio direto no Paraguai. Revista Brasileira de Ciência do Solo, volume 31, p. 985-994, 2007. DOI: 10.1590/S0100-06832007000500015. 